\title{
Innovations in Information Technology Classes in Primary School Based on Micro Courses
}

\author{
Shaohua $\mathrm{Nie}^{1}$ \\ ${ }^{1}$ Linyi University, Linyi, Shandong Province, China
}

Keywords: Micro courses; information technology; classroom innovation.

\begin{abstract}
At present, innovations and reforms are urgently needed in information technology education. The traditional teaching methods are difficult to stimulate students' interests and meet their existing needs. Nowadays, the "micro courses" teaching method has received much attention and researches from academic circle because of its educational philosophy of "starting from a small point, arousing students' interests, focusing on key information and satisfying individuals' characteristics". Reform and exploration on information technology teaching based on micro courses create a new teaching mode from microscopic view. Through online learning and mobile learning, micro courses can inject new vigor and vitality, provide guidance on teaching modes, and improve the teaching levels of primary schools.
\end{abstract}

\section{Micro Courses and Theoretical Basis}

The definition of micro courses. Connotation of micro courses. In recent years, micro courses are applied in many fields of education. But there's no clear definition on that item. In this paper, we use the definition of micro courses proposed in 2014 by Professor Xiao-yong Hu, one of the scholars who earliest proposed "constructing high-quality micro courses based on knowledge points" in China (2008) and Tie-sheng Hu, the founder of micro courses. "Micro courses are high quality micro learning resources which are carefully designed and developed based on the knowledge of a subject (such as knowledge points, skill points and emotion points) or combined with some teaching elements and links (such as teaching targets, introduction and evaluation activities). The core carriers of micro course are micro teaching videos."

Characteristics of micro course. Intuitive objects. Analyzing from the perspective of teaching media, the core carriers of micro course are micro teaching videos; compared with other media, teaching objects represented in videos are more intuitive, vivid and interesting. It is easier for intuitive objects to arouse students' learning interests. Students can learn knowledge according to their own situation. They can play and pause the video at any time, and repeat the video to achieve learning goals.

The concentration of themes. Analyzing from the perspective of learners' visual laws, although most micro videos are no longer than 5-8 minutes, they are concentrated essence with prominent topics. The intelligent points in micro courses are more prominent, which can better meet students' cognitive needs.

Diversified methods. From the view of information expression methods, through the usage of wonderful texts, pictures, animations, sounds and other multimedia means, micro course, micro courses can not only effectively convey the teaching content, but also effectively improve students' memorizing, understanding and thinking abilities.

Students' subjectivity. From the perspective of curriculum design, micro courses are designed and constructed by teachers after summarizing key and difficult points of lessons according to students' cognitive characteristics, and then presented through concise explanation and demonstration modes. They are suitable for students' autonomous learning and cooperative learning, and can cultivate students' innovation consciousness as well as innovation abilities.

Theoretical basis of micro courses. Constructivism learning theory. Constructivism learning theory advocates that students are the center of education; knowledge is not an entity, since it cannot exist without human beings. Constructivism emphasizes the process of "knowledge construction". 
Advocators of constructivism leaning theory believe that "before students entering the classroom, they have stored a great deal of experiences in their minds, which are the growing points of new knowledge. The process of students' learning is the process of constructing meaning". Teachers should take full account of students' original knowledge foundation. Knowledge should not be taught by teachers, but be actively constructed by students through cooperation, discussion and exchange in certain learning situations and with the guidance of necessary information resources.

The application of constructivism theory into information technology education fully reflects the dominant position of students. Through designing questioning situations and solving practical problems, students can experience the process of information processing, and carry out exchanges as well as cooperation, which will greatly eliminate the drawbacks of traditional teaching methods, and help teachers to achieve quality education and innovation education through the effective implementation of micro teaching.

Cognitive development theory. According to Piaget's theory of cognitive development stages, children's psychological development is the process of constantly reconstructing experience. Children's cognitive development process can be divided into four stages, "sensorimotor stage, pre-operational stage, concrete operational stage, formal operational stage". Information technology courses in primary school starts from the third grade, while students' cognitive levels are still in the stage of concrete operation. They have simple logic reasoning abilities, but these abilities do not have real operational properties; they are mostly limited in specific things and experiences.

Compared with traditional lecturing and PPT presentation, micro teaching is more vivid and interactive. It can represent teaching objects more concretely, and show the appearances of things. Thus, micro teaching can attract students' attention, arouse their interests, and help them to better understand and remember things. The teaching form based on micro curriculum is in line with the age and psychological characteristics of primary school students, and can change the dull and boring classroom climate based on traditional teaching methods of presenting symbols.

Audio-visual education theory. The audio-visual education theory was proposed by the American educator, Edgar Dale in 1946. In his theory of "cone of experience", or experience pyramid, human experiences can be divided into 3 categories, namely "experience of practice", "experience of watching", and "abstract experience". Compared with abstract symbols of "language", the audio-visual media means of "video" and "recording" are located in the middle part of the pyramid. They are easier for students to accept, and can break through the limit of time and space, so as to make up for the deficiencies of direct experiences. Experimental psychologist Treicher once made two famous psychological experiments. One is the experiment about sources of human's knowledege; the other is about human's memory persistence. Experiment results show that, information obtained through a variety of sensory stimulations is much stronger than information obtained through simply listening.

The theory of multiple intelligences. The United States Harvard University psychologist and educator Howard Gardner proposes the theory of multiple intelligences. In Gardner's opinion, humans have eight different kinds of intelligence; these eight kinds intelligence are closely related and relatively independent of one another. Everyone has nine kinds of multiple intelligences which are unique and different from each other; the multiple intelligences reflect peoples' development potentials, while these potentials can only be unlocked in appropriate contexts. "The different combinations of these intelligences show the intellectual differences between individuals; the starting point of education is to help students become smarter in some aspects". "The core of intelligence is the ability to solve problems in real life and to create products needed by the society." Gardner's intelligence theory has important guiding significance for schools to carry out modern information technology education.

\section{The Satisfaction of Micro Courses on Teaching Reform of Information Technology Courses in Primary School}

Meeting the requirements of new curriculum standards for basic information technology education. With the continuous progress of basic education reform, the Ministry of Education has 
paid more and more attention to information technology education, and introduced new information technology curriculum standards. The new curriculum standard requires reform in traditional teaching and learning methods in information technology education. According to the new standards, teachers need to start from actual teaching situations, try new teaching methods and techniques, and give full play to the dominant position of students, in order to effectively improve students' information literacy and innovation ability. Application of micro course has aroused widespread concern in education researchers, authorities and teachers. The application of micro courses in education is inevitable; it is also believed that information technology can adapt to new curriculum standards, and effectively improve the efficiency of classroom teaching.

Meeting primary school students' inner psychological needs in learning information technology. The traditional information technology courses in primary school mainly take the teaching mode of "explaining, performing and practicing". Although this mode has significant values in students' learning of scientific knowledge and skills, its disadvantages of large capacities, poor flexibility and adaptability are inevitable. For pupils, their durations of attention are relatively short, while their self-control abilities and learning abilities are relatively poor. Thus, traditional teaching methods will inevitably affect their learning interests to a certain extent; it is difficult to realize teaching effects. Micro curriculum, however, is a new teaching mode and teaching resources form; it has characteristics of short, clear, strong performances, easy to accept and suitable for self-study. Design and development of micro courses which are suitable for information technology courses and primary school students' learning needs will help to change the traditional information technology courses, as well as teachers' teaching methods and students' learning ways, so as to improve students' learning interests and learning effects.

\section{Teaching Design in Information Technology Micro Courses in Primary School}

Through the study of relevant literature on instructional design models, it is found that ADDIE teaching model has unique advantages in guiding micro curriculum design. According to characteristics of primary school information technology curriculum, we construct the curriculum design model of micro primary school information technology courses based on ADDIE production mode.

Preliminary analysis of micro courses. The preliminary analysis is the first step in micro curriculum designing. It is necessary to analyze the learning needs of students carefully, and then determine the objectives of micro courses in consideration of pupils' learning style, learning process and cognitive characteristics in courses supported by multimedia network. It does not only determine the direction of micro courses designing, but also affects the implementation and evaluation of micro courses. After determining the targets of learning, teachers should focus and decompose the targets, in order to lay a good foundation for the follow-up designing, development and implementation.

The design of micro courses. After the preliminary analysis of micro courses, firstly, teachers need to design audio-visual materials on intelligent points of the course through mind maps, flow charts, tables, pictures, animations, as well as other audios and videos. Intelligent points should be concisely expressed in these materials. Then, they need to design the procedure of explanation; perfect explanation plays a very important role in successful primary school information technology micro courses. It is necessary to carefully design the procedure, and strive to achieve the accurate and expressive explanation. Furthermore, micro curriculum courseware should be designed to string together the whole course. Finally, students' autonomous learning task lists should be provided to help students understand the contents, goals, tasks, as well as confusions and suggestions of the micro course. Charts should also be made for topic teaching.

The production of micro courses. According to existing production methods, there are three ways to produce micro courses: micro videos taken by cameras and mobile phones; videos produced by screen recording software like Camtasia Studio and Adobe Captivate; videos converted from PPT and other teaching materials. Micro videos for primary school information technology courses can be produced by above three methods according to specific contents. For instance, micro videos on basic knowledge can be recorded by photography technology; micro courses on software operations and 
procedural knowledge can be recorded through screen recording techniques. After recording, teachers can use video editing software to edit the micro videos, and then choose a suitable platform to release the videos with designed tasks.

\section{Teaching Methods in Information Technology Micro Courses in Primary School}

Micro courses are generally realized in primary school through the teaching method of "Flipped Classroom". There are three kinds of flipped classroom. The first is "flipped at home", which means students can use their micro course materials to study independently in their own home, and then communicate and discuss with classmates in the classroom. The second is "flipped at school"; the teacher allows students to watch the micro videos in the first class, and then asks them to communicate and interact with each other in the second class. The third is "flipped in classroom"; in the first half of class, students learn independently through micro course videos and task lists; while in the latter part of class, students interact with the teacher, and achieve teaching goals.

According to the actual situation of information technology education in primary school, it is believed that the primary school information technology curriculum is not suitable for "flipped at home" and "flipped at school" modes; it should adopt the approach of "flipped in classroom". Teachers can use this approach to divide the class into two parts. In the front part, students can use micro course materials and task lists to carry out autonomous learning; in the latter part, students explore the learning material and cooperate with each other under the guidance of the teacher.

The front part of class --- students' autonomous learning. Teaching tasks include:

1 , release micro video and task list;

2, students watch the video and carry out autonomous learning;

3, students ask questions;

4, the teacher collects and sorts out students' questions.

By watching micro course videos, students are required to complete their tasks according to the requirements of autonomous learning. For students, the main objective of this phase is to grasp basic concepts and knowledge in this lesson, and record their problems, confusions and gains when watching micro course videos. Then they need to examine their own learning degrees according to the task list. In this stage, the teacher is an observer, follower and collector of questions. The teacher has more time and energy to observe and understand students' learning situations; thus, the teacher can better focus on students with real needs, and more accurately grasp students' learning problems.

The latter part of class --- teacher-guided cooperative inquiry. Teaching tasks include:

1, problem explanation and analysis to clear up confusion;

2, appropriate teaching and learning activities;

3, exchange, summary, share and evaluation;

4, knowledge internalization and teaching reflection.

First of all, the teacher should explain students' common problems. Then, according to the observation and analysis of students' learning situations, as well as the requirements of the course, the teacher can organize classroom teaching and learning activities such as group discussion, collaborative inquiry, individual counseling, personal presentation and team reporting. Finally, these classroom teaching and learning activities should be summarized and evaluated to further strengthen students' internalization of knowledge, and effectively cultivate their information literacy and creativity. After the implementation of "flipped in classroom" method, teachers should reflect the teaching process in time, trying to make up for deficiencies in this course, and constantly improve the teaching and learning method of "flipped in classroom".

The key to solve teaching problems in primary school's information technology courses is to reconstruct the teaching mode. Under the guidance of cognitive flexibility theory, reform on teaching mode of primary school information technology courses is discussed. In the environment of IT-based classroom teaching, the information resources construction mode in primary school information technology courses is changed, so as to transfer the teaching mode and realize innovative teaching and learning. The establishment of new teaching model will effectively solve existing problems in information technology courses in primary schools, and improve the teaching effects. 


\section{References}

[1] Z.T. Zhu, H. Zhang, X.Q. Gu, Micro learning--a practical model of informal learning, J. China Educational Technology. 2 (2008) 10-13.

[2]X.S. Wei, Construction ideas from micro class to flipped classroom, J. Information Technology Education in Primary and Secondary School. 12 (2004).

[3] K.W. Xiong, Meaning and development of "subject plus self-help" information technology courses in primary school, J. China Information Technology Education.9 (2008) 